\title{
Tibial Artery
}

National Cancer Institute

\section{Source}

National Cancer Institute. Tibial Artery. NCI Thesaurus. Code C12824.

Any of the tibial arteries including the anterior and posterior tibial arteries and the anterior and posterior recurrent tibial arteries. 